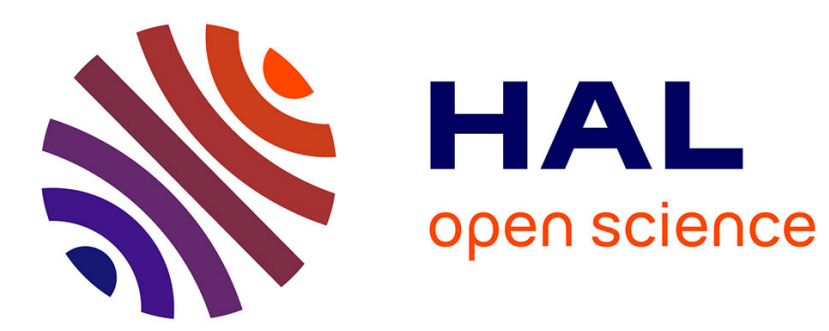

\title{
A COMPARISON OF EXPERIMENT AND THE THEORY OF CONTINUOUS ORDERING
}

\author{
Haydn Chen, J. Cohen
}

\section{To cite this version:}

Haydn Chen, J. Cohen. A COMPARISON OF EXPERIMENT AND THE THEORY OF CONTINUOUS ORDERING. Journal de Physique Colloques, 1977, 38 (C7), pp.C7-314-C7-327. 10.1051/jphyscol:1977762 . jpa-00217265

\section{HAL Id: jpa-00217265 https://hal.science/jpa-00217265}

Submitted on 1 Jan 1977

HAL is a multi-disciplinary open access archive for the deposit and dissemination of scientific research documents, whether they are published or not. The documents may come from teaching and research institutions in France or abroad, or from public or private research centers.
L'archive ouverte pluridisciplinaire HAL, est destinée au dépôt et à la diffusion de documents scientifiques de niveau recherche, publiés ou non, émanant des établissements d'enseignement et de recherche français ou étrangers, des laboratoires publics ou privés. 


\title{
A COMPARISON OF EXPERIMENT AND THE THEORY OF CONTINUOUS ORDERING
}

\author{
HAYDN CHEN $(*)$ \\ Materials Science Division, Argonne National Laboratory, Argonne, Ill. 60439, U.S.A. \\ and \\ J. B. COHEN \\ Department of Materials Science and Engineering, The Technological Institute \\ and Materials Research Center, Northwestern University, Evanston, Ill. 60201, U.S.A.
}

\begin{abstract}
Résumé. - La transformée de Fourier de l'Energie Libre d'Helmholtz $F(\mathbf{k})$, pour des fluctuations de composition de vecteur d'onde $\mathbf{k}$, a été obtenue dans le cas de plusieurs alliages ordonnés au-dessus de $T_{\mathrm{c}}$ en effectuant des mesures absolues, à haute température, de l'intensité due à l'ordre local le long des rangées de l'espace réciproque. Les monocristaux étudiés étaient les suivants : $\mathrm{Cu}_{3} \mathrm{Au}$, $\mathrm{Cu}-23$ atomes $\% \mathrm{Au}, \mathrm{Cu}-18,5$ atomes $\% \mathrm{Au}$, et $\mathrm{CoPt}_{3}$. Les résultats sont comparés à la théorie des transformations continues et il apparaît que l'approximation harmonique linéaire est insuffisante. En particulier l'énergie due au gradient dépend fortement de $\mathbf{k}$. Ceci apparaît aussi à partir des mesures des temps de relaxation effectuées suivant différentes directions cristallographiques : ceux-ci varient moins que prévu avec la direction quand on néglige la variation de l'énergie due au gradient. Il est possible de mesurer l'énergie d'activation de l'interdiffusion en volume dans les alliages à basse température en effectuant des mesures de l'intensité absolue due à l'ordre local en fonction de la température et en mesurant ensuite les variations de cette intensité avec le temps lorsque la température varie. Les résultats sont donnés pour les alliages déjà cités et pour l'alliage Fe-29,2 atomes \% Al.

Cette recherche a été financée par la U.S. National Science Foundation grâce à un contrat no DMR 73-07549 A01 et par le Centre de Recherche des Matériaux de la Northwestern University subventionné par la National Science Foundation sous contrat no DMR 760157.
\end{abstract}

\begin{abstract}
The Fourier transform of the Helmholtz Free Energy $F(k)$, for composition fluctuations of wave vector $\mathbf{k}$, has been obtained for several ordering alloys above $T_{\mathrm{c}}$ by measuring the absolute X-ray diffuse scattering intensity due to local order, at high temperatures, along lines in reciprocal space. The single crystals examined were $\mathrm{Cu}_{3} \mathrm{Au}, \mathrm{Cu}-23$ at pct $\mathrm{Au}, \mathrm{Cu}-18.5$ at pct $\mathrm{Au}$, and $\mathrm{CoPt}_{3}$. The values obtained are compared to the theory of continuous transformations and it is found that the linear theory is satisfactory but the nearest-neighbour approximation is inadequate. In particular, the gradient energy is a strong function of $\mathbf{k}$. This is also indicated from measured relaxation times in different crystallographic directions; these vary less with direction than predicted when the dependence of the gradient energy on $\mathbf{k}$ is ignored. It is possible to measure the activation energy for interdiffusion in bulk alloy crystals at low temperatures by measuring the absolute intensity due to local order vs. temperature and then measuring changes in this intensity with time when the temperature is varied. Values are given for the above alloys and for Fe-29.2 at pct Al.
\end{abstract}

1. Introduction. - The theory of continuous transformations has recently been reviewed [1]. This theory is equally applicable to spinodal decomposition and continuous ordering. The relaxation time, $\tau$, for a composition fluctuation of wave vector $\mathbf{k}$ $(k=2 \pi / \lambda)$ where $\lambda$ is the wavelength of the fluctuation after a change in temperature $T$ is [2] :

$$
\tau^{-1}(\mathbf{k})=\frac{2 D}{f^{\prime \prime}} B^{2}(\mathbf{k}) F(\mathbf{k}) .
$$

(*) Formerly research assistant. Department of Materials Science and Engineering, The Technological Institute, Northwestern University, Evanston, Illinois, U.S.A.
Here, $D$ is the interdiffusion coefficient, $f^{\prime \prime}$ is the second derivative (with respect to composition) of the Helmholtz free energy and $F(\mathbf{k})$ is a Fourier component of the Helmholtz free energy, including chemical and elastic terms. The term $B^{2}(\mathbf{k})$ is a sum over-nearest neighbours. $r$.

$$
B^{2}(\mathbf{k})=\frac{1}{a^{2}} \sum_{r}[1-\cos (\mathbf{k} \cdot \mathbf{r})] .
$$

Thus the free energy can be examined by studying the kinetics of changes in local order, or during the onset of long range order below the temperature for 
continuous ordering. The quantity $F(\mathbf{k})$ can also be investigated by measuring the equilibrium $\mathrm{X}$-ray intensity due to local order [1]. In Laue units :

$$
I_{\mathrm{SRO}}^{\mathrm{L} . \mathrm{U}}(\mathbf{k})=\frac{N_{\mathrm{v}} k_{\mathrm{B}} T}{c(1-c) F(\mathbf{k})}
$$

where $k_{\mathrm{B}}$ is Boltzmann's constant, $N_{\mathrm{v}}$ is the number of atoms per unit volume and $c$ is the atomic concentration of solute.

In its most simplified form, that is, when the basic diffusion equation is solved in the linear nearestneighbour approximation [3] :

$$
F(\mathbf{k})=f^{\prime \prime}+2 \eta^{2} M(\mathbf{k})+2 K B^{2}(\mathbf{k}) .
$$

The term $K$ is the gradient energy coefficient which is negative for ordering systems (as they prefer a large gradient in composition). The second term is the elastic energy $: \eta=\frac{1}{a} \frac{\partial a}{\partial c}$, where $a$ is the lattice parameter, and $M(\mathbf{k})$ is an effective elastic modulus. For the short waves involved in ordering this needs to be calculated from a force-constant model (see Appendix). For higher-neighbour interactions the gradient energy becomes a function of $\mathbf{k}[4,5,6]$ and Eq. (3) becomes :

$$
F(\mathbf{k})=\frac{N_{\mathrm{v}} k_{\mathrm{B}} T}{c(1-c)}+2 V(\mathbf{k})+2 \eta^{2} M(\mathbf{k}) .
$$

The first term in Eq. ( $4 a)$ is the entropy of mixing of an ideal solution. For crystal structures with a center of symmetry :

$$
V(\mathbf{k})=\sum_{p} V_{p}-\sum_{p} V_{p}[1-\cos (\mathbf{k} \cdot \mathbf{r}(p))] .
$$

The term $p$ represents a sum over interatomic vectors with components $p_{1}, p_{2}, p_{3}$. The pair energy is $V_{p}$. The second sum in Eq. ( $4 b)$ is the more exact gradient energy term (which divided by $B^{2}(\mathbf{k})$ we shall call $K(\mathbf{k}))$ whereas the first is part of $f^{\prime \prime}$ in Eq. (3).

As Cook has pointed out [1], most studies of continuous transformations have been concerned with spinodal decomposition and very little is known about continuous ordering. Even for spinodal decomposition, although the wavelength dependence of $\tau$ (Eq. (1a)) has been examined in many papers as well as the temperature dependence, and values of $K / f^{\prime \prime}$ have been determined based on the nearest-neighbour approximation, the dependence of $\tau$ on $\mathbf{k}$ has not been studied. Furthermore, in only one case [7] were absolute intensities employed so that $K$ and $f^{\prime \prime}$ could be separately measured in one experiment. Even less information is available for ordering systems. Paulsen [8] employed films of alternate layers of $\mathrm{Cu}$ and $\mathrm{Au}$ to study the decay of waves in this system. In particular, the wavelength and temperature (but not the crystallographic) dependence were examined.
Naumora et al. [9] employed bulk Fe-Al alloys but examined only quenched specimens to study kinetics, and did not correct the measured diffuse scattering for effects due to atomic displacements.

Here, studies are reported of the absolute equilibrium short-range order intensity vs. temperature and the kinetics in different crystallographic directions and for different wavelengths, when the temperature of a single crystal is changed $\approx 25^{\circ} \mathrm{C}$ from various temperatures (above $T_{\mathrm{c}}$ ). This situation corresponds to such a small change in local environment that the linear theory should be applicable. This will allow a test of the dependence of the gradient energy on $\mathbf{k}$. All data was taken at high temperatures. The diffuse intensity due to local order was separated from that due to size effects. The results indicate that the $\mathbf{k}$ dependence of the gradient energy (which comes from higher-neighbour interactions) is important.

This study also indicates that measurements of the diffuse scattering from bulk alloy single crystals can be employed (as well as thin films) to quantitatively examine the theory and to obtain information on diffusivities at low temperatures.

2. Experimental methods. - 2.1 Materials. Single crystals of $\mathrm{Cu}_{3} \mathrm{Au}, \mathrm{Cu}-23$ at pct $\mathrm{Au}, \mathrm{Cu}-18.5$ at pet $\mathrm{Au}, \mathrm{CoPt}_{3}$ and $\mathrm{Fe}-29.2$ at pct $\mathrm{Al}$ were studied. The compositions were known to \pm 0.1 at pct or better. Their growth, characterization, and preparation for X-ray measurements has been described elsewhere [10-14]. These were all in the form of plates $3 \times 10^{-4}-5 \times 10^{-4} \mathrm{~m}$ thick. The effect of surface roughness was measured by examining the fluorescence by $\mathrm{MoK}_{\alpha}$ vs. $2 \theta[15,16]$ and all X-ray data was corrected for this effect. Transition temperatures were defined by examining the intensity of a superlattice reflection. A sharp discontinuity occurs at $T_{\mathrm{c}}$ for $\mathrm{Cu}_{3} \mathrm{Au}$ as the order-disorder transition is first order. For $\mathrm{CoPt}_{3}$ and $\mathrm{Cu}-18.5$ at pct $\mathrm{Au}$ there is a two-phase region and the change in slope of the intensity vs. temperature was employed. The Fe-Al alloy undergoes a higher order transition and the inflection point was employed to crudely define the transition.

2.2 X-RAY SYSTEM. - The diffractometer was a GE XRD-5 system modified to utilize a doubly bent graphite incident beam monochromator [17]. A specimen was held on a eucentric quarter circle goniometer in the $\chi=90^{\circ}$ configuration on a resistance heated metal stage covered with a watercooled Be hemisphere $7.5 \times 10^{-4} \mathrm{~m}$ thick [18]. The system was evacuated to $2 \times 10^{-5} \mathrm{~mm}$ of $\mathbf{H g}$ or less. Temperature was controlled to $\pm 0.25{ }^{\circ} \mathrm{C}$ or better with a feedback controller system. Two thermocouples were placed at different points under a single crystal to check for any gradients. A receiving slit and scatter slit were employed; total horizontal 
divergence was 0.75 to $1.20^{\circ} 2 \theta$. Total vertical divergence was 2 to $2.70^{\circ} 2 \theta$ (measured with a perfect silicon crystal [17]). The range of a diffuse scattering peak was 3 to $7^{\circ} 2 \theta$ at half height, depending on the crystal.

The radiation was $\mathrm{CoK}_{x}$ at $50 \mathrm{kV}, 7 \mathrm{~mA}$. The half-wavelength component was 0.1 pct. All intensities were measured for $10^{5}-10^{6}$ counts (in a monitor detector) from a $\mathrm{V}_{2} \mathrm{O}_{5}$ film placed in the exit beam from the monochromator, thereby minimizing effects of changes in air density, X-ray tube output and any slight misalignment of the monochromator during the measurements.

The entire system was controlled by a $16 \mathrm{~K}$ Digital Equipment Corporation PDP8-E minicomputer with a twin tape unit (to store computed angles $\chi, \varphi, 2 \theta$ and data). This system carried out the $\chi$ and $\varphi$ tilts of the crystal, the $2 \theta$ motions of the detector, counting in both detectors, and monitored the temperature through a digital voltmeter. The data were automatically corrected for the measured deadtime of the counting system $[19,20]$.

2.3 Measurements at equilibrium. - Care was taken to assure equilibrium at any temperature by counting to a statistical error of at least 0.5 pct several times. Some 20 minutes were required to equilibrate well away from $T_{\mathrm{c}}$, but times up to a few days were needed near the transition.

Data were corrected for surface roughness, measured polarization factor [21], and air scattering was subtracted (determined with a $\mathrm{Pb}$ beam trap replacing the specimen). The results were then placed on an absolute scale by determining the intensity of the direct beam. This was done by integrating peaks from an $\mathrm{Al}$ powder compact, correcting for thermal diffuse scattering and comparing the result to calculated values [20]. Calculated Compton scattering was then subtracted and the data reduced to Laue units per atom by dividing by $N_{\mathrm{v}} c(1-c)\left|f_{\mathrm{A}}-f_{\mathrm{B}}\right|^{2}$. The scattering factors employed in these calculations can be found in reference [22]. (For the case of $\mathrm{Cu}_{3} \mathrm{Au}$ these were corrected for Debye-Waller factors, but in the other alloys, these factors were not known.)

For the $\mathrm{Cu}-\mathrm{Au}$ alloys and $\mathrm{CoPt}_{3}$ the ordering transformation is from an $\mathrm{Al}$ (fcc) structure to $\mathrm{Ll}_{2}$; superstructure reflections appear below $T_{\mathrm{c}}$ at 001 , 011 , etc., in reciprocal space. For Fe-29.2 pct Al the change is from $\mathrm{B} 2(\mathrm{CsCl})$ to $\mathrm{DO}_{3}$ cell, with superstructure reflections at $1 / 21 / 21 / 2$, etc. Accordingly, in the former case the diffuse scattering due to local order was examined along $\langle 00 h\rangle$ and $\langle 0 h h\rangle$ lines in reciprocal space, whereas in the latter it was examined only along the $\langle h h h\rangle$ direction. The intensity due to local order needed to determine $F(\mathbf{k})$ in Eq. (2) was separated from that due to scattering from average and mean-square atomic displacements from the average lattice sites, following the method of Borie and Sparks [22-24]. For $\mathrm{Cu}-\mathrm{Au}$ alloys and $\mathrm{CoPt}_{3}$ (Al structure), with the total elastic diffuse intensity in Laue units per atom written as $I_{\mathbf{T}}^{\mathrm{L} . \mathrm{U} .}$ :

$$
\begin{aligned}
& I_{\mathrm{SRO}}^{\mathrm{L} . \mathrm{U} \cdot(00 h)}=I_{\mathrm{T}}^{\mathrm{L} . \mathrm{U}}(00 h)-\frac{h}{2}\left[I_{\mathrm{T}}^{\mathrm{L} \cdot \mathrm{U}}(h, 0,2)-I_{\mathrm{T}}^{\mathrm{L} . \mathrm{U}}(2-h, 0,2)\right]+\left(\frac{h^{2}-2 h}{8}\right) \times \\
& \times\left[I_{\mathrm{T}}^{\mathrm{L}} \cdot \mathrm{U} \cdot(2,0,4-h)-2 I_{\mathrm{T}}^{\mathrm{L}} \cdot \mathrm{U} \cdot(2-h, 0,2)+I_{\mathrm{T}}^{\mathrm{L}} \cdot \mathrm{U} \cdot(h, 0,2)\right] \text {, } \\
& I_{\text {SRO }}^{\mathrm{L} . \mathrm{U}}(h h 0)=I_{\mathrm{T}}^{\mathrm{L}} \cdot \mathrm{U}(h h 0)-h\left[I_{\mathrm{T}}^{\mathrm{L}} \cdot \mathrm{U} \cdot(h h 0)-I_{\mathrm{T}}^{\mathrm{L}} \cdot \mathrm{U} \cdot(2-h, h, 0)\right]+ \\
& +\left(\frac{h^{2}-2 h}{4}\right)\left[I_{\mathrm{T}}^{\mathrm{L} \cdot \mathrm{U} \cdot} \cdot(4-h, h, 0)-2 I_{\mathrm{T}}^{\mathrm{L} \cdot \mathrm{U} \cdot} \cdot(2-h, h, 0)+I_{\mathrm{T}}^{\mathrm{L}} \cdot \mathrm{U} \cdot(h h 0)\right]
\end{aligned}
$$

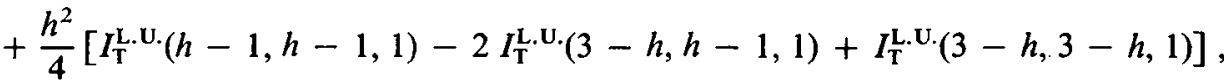

with $h$ taken from 1 to $3 / 2$. For Fe-29.2 pet Al (B2 structure) with $h$ from $1 / 2$ to 1 :

$$
\begin{aligned}
& I_{\mathrm{SRO}}^{\mathrm{L} \cdot \mathrm{U}}(h h h)=I_{\mathrm{T}}^{\mathrm{L} \cdot \mathrm{U}}(h h h)+\frac{6 h-9 h^{2}}{8} I_{\mathrm{T}}^{\mathrm{L} \cdot \mathrm{U} \cdot}(2-h, h, h)+\frac{3 h^{2}}{4} I_{\mathrm{T}}^{\mathrm{L} \cdot \mathrm{U} \cdot}(2-h, 2-h, h)+ \\
& +\frac{3 h^{2}-6 h}{8} I_{\mathrm{T}}^{\mathrm{L}} \mathrm{U} \cdot(2+h, h, h) \text {. }
\end{aligned}
$$

Similar separation equations are available for the various displacement terms [22]. These equilibrium measurements were made $v s$. temperature at the position of the superlattice reflection which occurs below $T_{\mathrm{c}}$, with sufficient counts so that the statistical error after separation was $1.5 \%$ or better. Measurements were also made along complete lines for each alloy at fixed temperatures; in this case, after separation the error was 8 pct or less.

2.4 Kinetic STUdies. - The value of $\tau(\mathbf{k})$ can be determined at various positions $\mathbf{k}$ in reciprocal space, in various crystallographic directions, and at various temperatures, by examining the kinetics 
of the change in intensity due to local order when the temperature is changed :

$$
\begin{aligned}
& \ln \left[I_{\text {SRO }}^{\mathrm{L} . \mathrm{U}} \cdot(\mathbf{k}, t)-I_{\mathrm{SRO}}^{\mathrm{L} . \mathrm{U}} \cdot(\mathbf{k}, \infty)\right]= \\
& =\ln \left[I_{\mathrm{SRO}}^{\mathrm{L}} \cdot \mathrm{U} \cdot(\mathbf{k}, 0)-I_{\mathrm{SRO}}^{\mathrm{L} . \mathrm{U}}(\mathbf{k}, \infty)\right]-t / \tau(\mathbf{k}) .
\end{aligned}
$$

Because ratios are employed, the absolute intensity is not required. Furthermore, background and Compton scattering are independent of time, so that these cancel in the differences. The measured intensity is merely corrected for angular factors (surface roughness, polarization factor and $\left.\left|f_{\mathrm{A}}-f_{\mathrm{B}}\right|^{2}\right)$. The separation equations, $(5 a-5 c)$ were utilized to remove displacement effects, with $I_{\mathrm{T}}^{\mathrm{L}} \cdot \mathrm{U}$. replaced by

$$
\Delta I_{\mathrm{RAW}}=\left(\frac{\left[I_{\mathrm{RAW}}(\mathbf{k}, t)-I_{\mathrm{RAW}}(\mathbf{k}, \infty)\right]}{\text { ANGULAR FACTORS }}\right) .
$$

Eq. (1a) may be rewritten as :

$$
[\tau(\mathbf{k}) F(\mathbf{k})]^{-1}=\frac{2 B^{2}(\mathbf{k})}{f^{\prime \prime}} D_{0} \mathrm{e}^{-Q / k_{\mathbf{B}} T}
$$

Taking logarithms of both sides of Eq. (7a) :

$$
\begin{aligned}
& \ln \left[\tau(\mathbf{k})^{-1} / F(\mathbf{k})\right]= \\
& \quad=\ln 2 B^{2}(\mathbf{k})-\ln f^{\prime \prime}+\ln D_{0}-Q / k_{\mathrm{B}} T .
\end{aligned}
$$

From the slope of the left hand side of Eq. (7b) vs. $1 / T$ the activation energy for diffusion, $Q$ may be obtained. From the intercept and with $f^{\prime \prime}$ determined from equilibrium intensities (see Eq. (2)) or from thermodynamic data, $D_{0}$ can be measured.

A specimen was brought to one temperature level and equilibrated, checking the total counts $\left(10^{4}-10^{5}\right)$ for fifteen minutes or more. The temperature was then changed $15-25^{\circ} \mathrm{C}$ (except for $\mathrm{Fe}-\mathrm{Al}$, see below) and data was sampled at one position (k) every 1-20 seconds depending on the temperature and crystal. (The monitor was not employed.) The specimen was then brought back to the original temperature level, re-equilibrated and the process repeated for another point needed in the separation equations, cycling again for the other points needed. The entire process was repeated until $1.8 \times 10^{3}-10^{5}$ counts were collected at each point. This operation, including cycling, was carried out by the minicomputer system. Typical data are shown in figure $1 a$. This data was fitted with smooth curves and separated, resulting in the filled circles in figure $1 b$; the slope yields $\tau$. (The crosses in this figure represent unsmoothed differences; without the smoothing the relaxation times were the same, but the errors were $\pm 5 \%$ of $\tau$, rather than the $\pm 0.3 \%$ after smoothing.)

All measurements except those carried out on $\mathrm{Cu}_{3} \mathrm{Au}$, were made in a vacuum in the high-temperature attachment previously described. The furnace was within $0.25{ }^{\circ} \mathrm{C}$ of equilibrium in 40 seconds after a $\sim 25{ }^{\circ} \mathrm{C}$ change, and the relaxation times

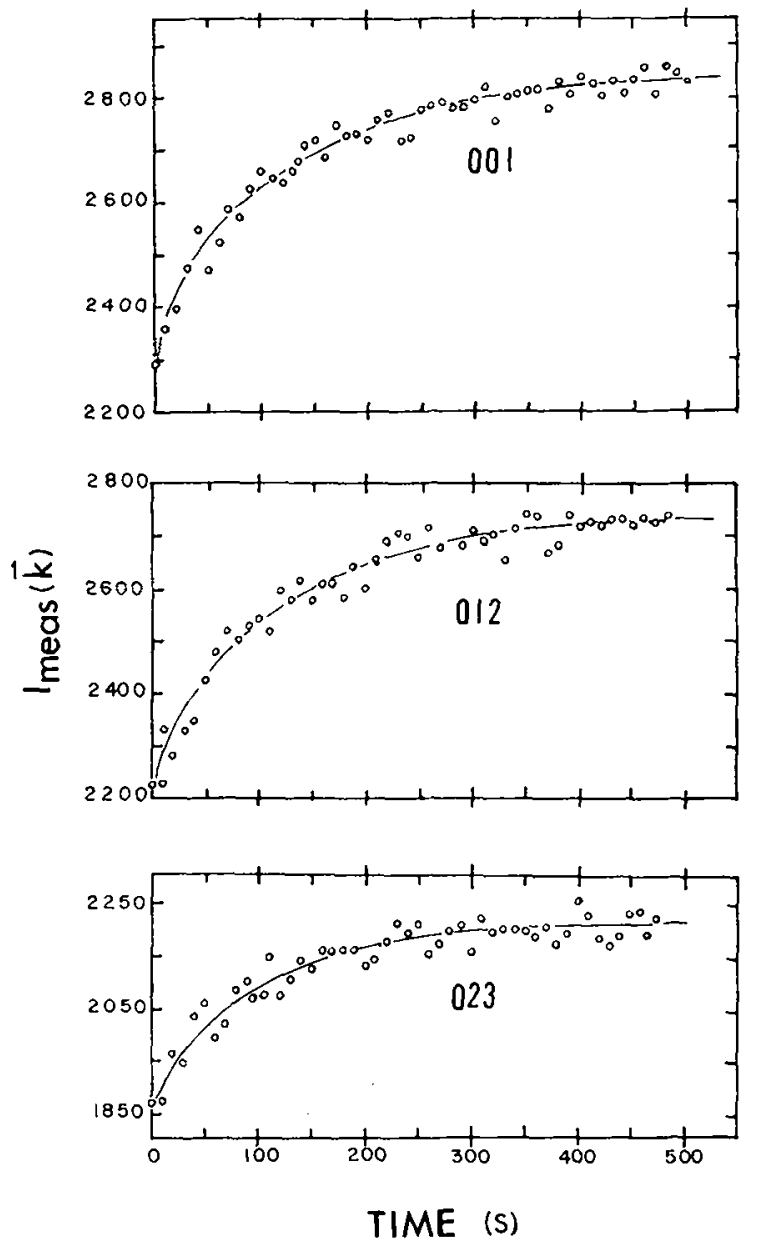

FIG. 1a. - Kinetics of the change in measured diffuse intensity ( $I_{\text {meas }}$ in counts) for $\mathrm{Cu}-18.5$ at pct $\mathrm{Au}$, on changing the temperature from $355^{\circ} \mathrm{C}$ to $330^{\circ} \mathrm{C}$. Measured intensities vs. time at 001,012 and 023 positions. Smoothed curves at each position are also shown. (These arc the only three positions needed to separate $I_{\mathrm{SRO}}$ at 001 .)

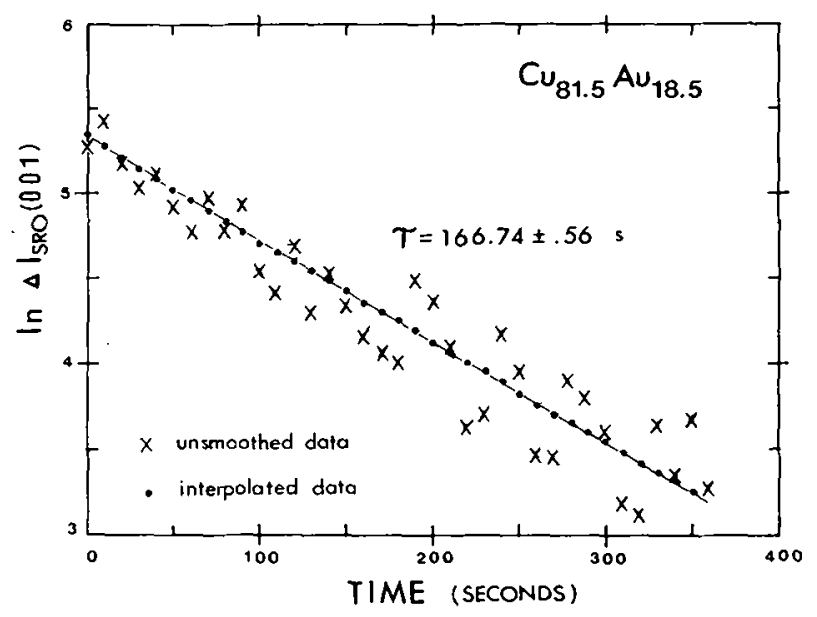

FIG. 1b. - The scparated short range order intensity on a logarithmic scale, In $\Delta I_{\text {SRo }}(001)$, vs. time. Filled circles : points from data on curves in $(a)$ separated into effects due to size and $I_{\text {SRo }}$ as described in the text. Crosses : from unsmoothed data points in $(a)$. 
(for the intensity to fall to $1 / e$ of its original value) were longer. For $\mathrm{Cu}_{3} \mathrm{Au}$, the relaxation times were short $(\approx 10 \mathrm{~s})$ and a static atmosphere of purified helium was introduced into the camera, reducing the total time for a change in temperature of $25^{\circ} \mathrm{C}$ to 13 seconds.

3. Results and discussion. - 3.1 Equilibrium Studres. - 3.1.1 Temperature Dependence. - The term $T / I_{\mathrm{SRO}}^{L} \mathrm{U}$ at $\mathrm{k}^{*}$, the position of a superlattice reflection that would occur below $T_{c}$, was found to be linear vs. $T$ (except near $T_{\mathrm{c}}$ for $\mathrm{Cu}_{3} \mathrm{Au}$, where heterophase fluctuations appear [25]). Thus $F\left(\mathbf{k}^{*}\right)$ (from Eq. (2)) can be written as $\Delta S_{\mathrm{m}}^{\prime \prime}\left(T-T_{\text {instability }}\right.$ ) where $T_{\text {instability }}$ is the temperature for continuous ordering obtained by extrapolating $F\left(\mathbf{k}^{*}\right)$ to zero. The slopes, $\Delta S_{\mathrm{m}}^{\prime \prime}$, which correspond to the second derivative of the entropy of mixing are given in table I. If the system can be described in the linear,

\section{TABLE I}

Proportional constant, $\Delta S_{\mathrm{m}}^{\prime \prime}$, determined from $T / I_{\text {SRO L }}^{\mathrm{L}} \cdot\left(\mathbf{k}^{*}\right)$ vs. $T$

\begin{tabular}{|c|c|c|c|}
\hline \multicolumn{4}{|c|}{$\Delta S_{\mathrm{m}}^{\prime \prime}\left[\frac{N_{\mathrm{v}} k_{\mathrm{B}}}{c(1-c)}\right]$} \\
\hline Alloy & Measured & $\begin{array}{l}\text { Estimated } \\
\text { from Data } \\
\text { in Ref. [26] }\end{array}$ & $\begin{array}{l}\text { Temperature } \\
\text { Range }\left({ }^{\circ} \mathrm{C}\right)\end{array}$ \\
\hline $\mathrm{Cu}_{3} \mathrm{Au}$ & $1.006( \pm 0.002)$ & 3.3 & $388.25-421.50$ \\
\hline $\mathrm{Cu}_{81.5} \mathrm{Au}_{18.5}$ & $1.203( \pm 0.008)$ & 2.7 & $331.00-369.30$ \\
\hline $\mathrm{CoPt}_{3}$ & $0.528( \pm 0.004)$ & 2.7 & $683.50-720.30$ \\
\hline $\mathrm{Fe}_{70.8} \mathrm{Al}_{292}$ & $1.90( \pm 0.18)$ & 4.2 & $540.50-575.00$ \\
\hline
\end{tabular}

nearest-neighbour approximation previously mentioned (see Eq. (3)) and also if the elastic free energy and gradient energy are essentially independent of temperature over the range studied it is easy to show that :

$$
\Delta S_{\mathrm{m}}^{\prime \prime}=\frac{N_{\mathrm{v}} k_{\mathrm{B}}}{c(1-c)}\left[1+\frac{\mathrm{d} \ln \gamma}{\mathrm{d} \ln c}\right]
$$

where $y$ is the activity coefficient of the solute. Hence, comparisons with measured thermodynamic data are also shown in the table. The poor comparisons are the first indications in this study that the simple ncarest-neighbour approximation is inadequate.

$3.1 .2 \mathrm{k}$ Dependence. - For the nearest-neighbour approximation, from Eqs. (2) and (3) :

$$
\begin{aligned}
\frac{N_{\mathrm{v}} k_{\mathrm{B}} T}{c(1-c) I_{\mathrm{SRO}}^{\mathrm{L} . \mathrm{U}}(\mathbf{k})}-2 \eta^{2} M(\mathbf{k}) & = \\
& =f^{\prime \prime}+2 K B^{2}(\mathbf{k}) .
\end{aligned}
$$

A typical set of data for this equation is shown in figure 2. Note particularly that along the $\langle h h 0\rangle$ direction (filled circles) the points do not fall along a straight line. (This was also the case for $\mathrm{Cu}-25$ at pct $\mathrm{Au}$ and $\mathrm{CoPt}_{3}$.) Ignoring this point for the moment, and performing a least squares fit to Eq. (9) yields the values of $f^{\prime \prime}$ and $K$ in table II. Comparisons of these values with data from thermodynamic studies (for $f^{\prime \prime}$ ) and with values calculated from pair potentials (for the gradient energy $K$ ) are fair. But if the data along the two lines is treated separately for the three alloys, $f^{\prime \prime}$ varies by as much as a factor of four, and $K$ by as much as a factor of two [22]. As $f^{\prime \prime}$ is a scalar and $K$ is a second rank tensor [29], the values must be the same in the two directions for this cubic material. The fit is not improved if a quasithree shell model is employed for the elastic modulus, rather than a near neighbor model (see the Appendix). Furthermore, if $K(\mathbf{k})$ is calculated for $\mathrm{Cu}_{3} \mathrm{Au}$ and pair potentials up to the sixth shell [21], this term varies by $30 \mathrm{pct}$ from $h=0.5$ to $h=1.0$ [22].

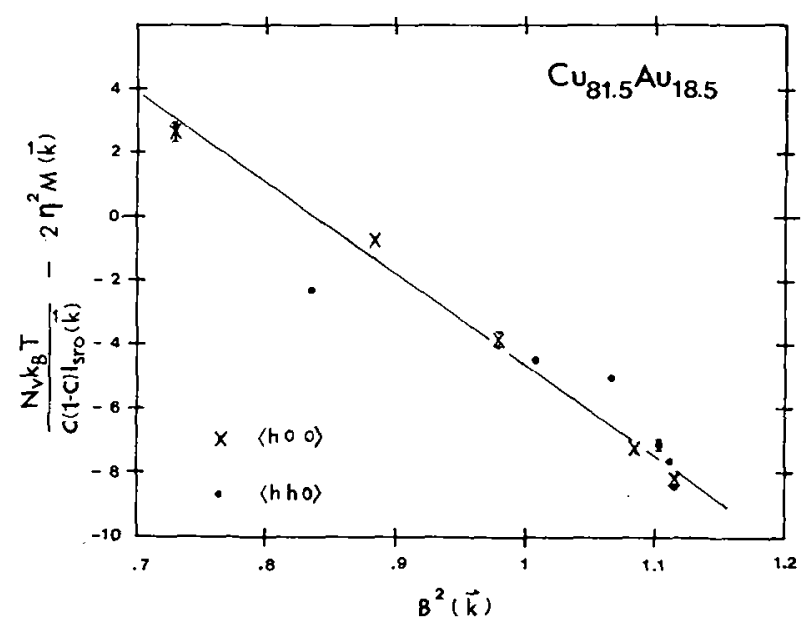

FIG. 2. - Typical plot of $\left[\frac{N_{v} k_{\mathrm{B}} T}{c(1-c) I_{\mathrm{SRO}}^{\mathrm{L} U}(\mathbf{k})}\right]$ vs. $B^{2}(\mathbf{k})$ for $\mathrm{Cu}_{81.5} \mathrm{Au}_{18.5}$ at $351.5^{\circ} \mathrm{C}$. (Crosses are for data along $\langle h 00\rangle$ directions while filled circles are for those along $\langle h h 0\rangle$.)

It appears much more satisfactory to take into account the variation of the gradient energy term with $\mathbf{k}$. This is done in table III for $\mathrm{Cu}_{3} \mathrm{Au}$, the only alloy studied for which pair potentials are available $[21,28]$ as well as the necessary thermodynamic studies [26]. (The measured pair potentials actually include the elastic free energy term $2 \eta^{2} M(\mathbf{k})$ and Langer's correction [30].) The fit along both lines seem reasonable. In table III a comparison is made of the calculated and measured gradient energy coefficient and the agreement is excellent.

It appears then that the gradient energy must be considered as a function of $\mathbf{k}$ for alloys with only short range order, even at high temperatures. It 
TABLE II

Experimentally determined and estimated $f^{\prime \prime}$ and $K$ for various alloys

\begin{tabular}{|c|c|c|c|c|}
\hline & \multicolumn{2}{|c|}{$f^{\prime \prime}\left(\mathrm{erg} / \mathrm{cm}^{3}\right) \times 10^{11}$} & \multicolumn{2}{|c|}{$K(\mathrm{erg} / \mathrm{cm}) \times 10^{-6}$} \\
\hline System & $\begin{array}{l}\text { Measure- } \\
\text { ment }\end{array}$ & $\begin{array}{c}\text { Estimation } \\
\text { from Ref. } \\
{[26,27]}\end{array}$ & Measurement & $\begin{array}{c}\text { Estimation } \\
\text { from Eq. }(4 b) \\
\text { at superlattice } \\
\text { positions }\end{array}$ \\
\hline - & - & - & - & - \\
\hline $\mathrm{Cu}_{3} \mathrm{Au}$ & $1.04( \pm 0.04)$ & 1.37 & $-7.8( \pm 1.4)$ & $\left\{\begin{array}{l}-5.29\left(^{a}\right) \\
-7.58\left({ }^{b}\right)\end{array}\right.$ \\
\hline $\mathrm{Cu}_{81.5} \mathrm{Au}_{18.5}$ & $2.05( \pm 0.03)$ & 1.12 & $-12.2( \pm 1.3)$ & not available (c) \\
\hline $\mathrm{CoPt}_{3}$ & $0.61( \pm 0.03)$ & $2.35\left(^{(d)}\right.$ & $-5.6( \pm 0.8)$ & not available ( $\left.{ }^{c}\right)$ \\
\hline $\mathrm{Fe}_{70.8} \mathrm{Al}_{29.2}$ & $0.31( \pm 0.01)$ & $2.93\left({ }^{d}\right)$ & $-1.0( \pm 0.4)$ & not available $\left({ }^{c}\right)$ \\
\hline
\end{tabular}

\section{TABLE III}

$F(\mathbf{k})$ and $K(\mathbf{k})$ at various positions $(\mathbf{k})$ in reciprocal space for $\mathrm{Cu}_{3} \mathrm{Au}$ at $420{ }^{\circ} \mathrm{C}$. The measured $F(\mathbf{k})$ and $K(\mathbf{k})$ obtained directly from $I_{\mathbf{S R O}}^{L . U .}(\mathbf{k})$ are shown for comparison

\begin{tabular}{|c|c|c|c|c|c|c|}
\hline & $\begin{array}{c}f^{\prime \prime} \\
\left(\mathrm{erg} / \mathrm{cm}^{3}\right) \\
\text { from Ref. }\end{array}$ & $K(\mathbf{k})(($ erg & $\left.\times 10^{-6}\right)$ & $B^{2}(\mathbf{k})$ & $\begin{array}{r}F(\mathbf{k})=f^{\prime \prime} \\
(\mathrm{erg} / \mathrm{cn}\end{array}$ & $\begin{array}{l}K(\mathbf{k}) B^{2}(\mathbf{k}) \\
\left.10^{11}\right)\end{array}$ \\
\hline $\mathbf{k}$ & $\left(\times 10^{11}\right)$ & $(*)$ & Measured & $\times 10^{17}$ ) & Estimated & Measured \\
\hline- & - & - & 一 & - & - & - \\
\hline$(0,0,1)$ & 1.37 & -5.29 & -6.00 & 0.1114 & 0.19 & 0.03 \\
\hline$(0,0,0.9)$ & 1.37 & -5.24 & -5.36 & 0.1087 & 0.23 & 0.20 \\
\hline$(0,0,0.8)$ & 1.37 & -5.07 & -5.03 & 0.1007 & 0.35 & 0.36 \\
\hline$(0,0,0.7)$ & 1.37 & -4.78 & -4.96 & 0.0884 & 0.53 & 0.49 \\
\hline$(0,0,0.6)$ & 1.37 & -4.35 & -5.47 & 0.0729 & 0.74 & 0.57 \\
\hline$(0,1,1)$ & 1.37 & -5.29 & -5.96 & 0.1114 & 0.19 & 0.04 \\
\hline$(0,0.9,0.9)$ & 1.37 & -5.27 & -5.89 & 0.1113 & 0.20 & 0.06 \\
\hline$(0,0.8,0.8)$ & 1.37 & -5.20 & -5.74 & 0.1104 & 0.22 & 0.10 \\
\hline$(0,0.7,0.7)$ & 1.37 & -5.09 & -5.61 & 0.1066 & 0.29 & 0.18 \\
\hline$(0,0.6,0.6)$ & 1.37 & -4.86 & -6.01 & 0.0981 & 0.42 & 0.19 \\
\hline$(0,0.5,0.5)$ & 1.37 & -4.44 & -5.98 & 0.0835 & 0.63 & 0.37 \\
\hline
\end{tabular}

(*) Calculated with a six shell approximation, Eq. (4b) and pair potentials in reference [21]. Using Moss' potentials (Ref. [28])

$$
K(001)=-6.55 \times 10^{-6} \mathrm{erg} / \mathrm{cm} . \quad K(0,0,0.7)=-4.99 \times 10^{-6} \mathrm{erg},\left(11 \mathrm{l} \text { and } K(0,0.7,0.7)=-5.62 \times 10^{-6} \mathrm{erg} \mathrm{cm}\right.
$$

is, therefore, to be expected that this dependence will be important in kinetic studies, as local order will increase during a quench.

3.2 Kinetic Studies. - 3.2.1 k Dependence. The temperature changes were selected to give a total change in intensity of $<25$ pct so that the total change in local concentration was the order of 13 pct or less. With these changes it was possible to make precise kinetic measurements at several $\mathbf{k}$ values, particularly for $\mathrm{Cu}-18.5$ at pet $\mathrm{Au}$ and $\mathrm{Cu}-23$ at pct $\mathrm{Au}$; for these alloys the temperatures above $T_{\mathrm{c}}$ are sufficiently low that the relaxation times were considerably longer than that of the heating stage. Some results are given in table IV where the dependence of $\tau$ on $\mathbf{k}$ is clearly indicated. Curiously, the relaxation time for scattering from mean square atom displacements $\left(\tau_{\mathrm{Rx}}\right)$ is less than that for local 


\section{TABLE IV}

Relaxation times at various $\mathbf{k}$ positions

\begin{tabular}{|c|c|c|c|}
\hline \multicolumn{4}{|c|}{$\mathrm{Cu}_{81.5} \mathrm{Au}_{18.5}$} \\
\hline$T\left({ }^{\circ} \mathrm{C}\right)\left({ }^{*}\right)$ & $\mathbf{k}$ & $\tau_{\text {SRO }}(s)$ & $\tau_{\mathbf{R x}}(\mathrm{s})$ \\
\hline $355 \rightarrow 330$ & $(0,0,1)$ & $166.74 \overline{(} \pm 0.56)$ & $145.24( \pm 1.52)$ \\
\hline $355 \rightarrow 330$ & $(0,0,1.1)$ & $98.49( \pm 0.87)$ & $91.15( \pm 2.33)$ \\
\hline $355 \rightarrow 330$ & $(0,1,1)$ & $165.05( \pm 0.86)$ & $144.00( \pm 2.21)$ \\
\hline $355 \rightarrow 330$ & $(0,1.1,1.1)$ & $130.36( \pm 1.27)$ & $120.50( \pm 2.98)$ \\
\hline $355 \rightarrow 330$ & $(0,1.2,1.2)$ & $68.03( \pm 1.50)$ & $\ldots\left({ }^{* *}\right)$ \\
\hline \multicolumn{4}{|l|}{$\mathrm{Cu}_{77} \mathrm{Au}_{23}$} \\
\hline$T\left({ }^{\circ} \mathrm{C}\right)$ & A & $\tau_{\text {SRO }}(s)$ & $\tau_{R x}(s)$ \\
\hline $395 \rightarrow 380$ & $(0,1,1)$ & $54.44( \pm 5.11)$ & $50.25( \pm 7.12)$ \\
\hline $395 \rightarrow 380$ & $(0,1.1,1.1)$ & $47.53( \pm 4.89)$ & $45.33( \pm 6.95)$ \\
\hline
\end{tabular}

(*) Arrows indicate the direction of temperature change.

$\left.{ }^{* *}\right) \tau_{\mathbf{R} x}$ at $0,1.2,1.2$ was too fast to be measured.

order, perhaps because these displacements involve thermal effects, as well as those due to atomic concentrations. The phonon spectra may be most sensitive to the initial changes in environment with a change in temperature.

The wavelength and crystallographic dependence of $\tau$ is illustrated in figure $3 a$ where the experimental data is compared to the predictions of the linear nearest-neighbor theory. The agreement is poor; considerable improvement is achieved if the calculation of $\tau(\mathbf{k})$ is made with the measured $F(\mathbf{k})$, figure $3 b$. Once again it is clear that the gradient energy is a strong function of $\mathbf{k}$.

It can be shown [22] that the reason investigators $[31,32]$ find a single relaxation time when employing resistivity measurements to obtain relaxation times during changes in local order is due to the fact that this measurement heavily weighs $\tau$ near the superlattice positions.

3.2.2 Temperature dependence. - Measurements were made only at the positions where superlattice reflections would occur below $T_{c}$. No separation of the data was made into $I_{S R O}$ and intensity due to atomic displacements, because at those positions the latter is 5 pct or less than the total and tests indicated that the relaxation times were unaffected.

3.2.2.1 Cu-18.5 at pet Au. - According to Eq. $(7 b)$, if $F(\mathbf{k})$ is linear vs. $T$ with the form

$$
\Delta S_{\mathrm{m}}^{\prime \prime}\left(T-T_{\text {instability }}\right) \text {. }
$$

then $\ln \left[\tau^{-1}(001) /\left(T-T_{\text {instability }}\right)\right] v s .1 / T$ should be linear $\left({ }^{1}\right)$. This appears to be the case in figure 4 , where $D_{0}$ and the activation energy for diffusion obtained from Eq. (7b) are also shown. The error in $D_{0}$ includes the estimated errors in $\Delta S^{\prime \prime}, f^{\prime \prime}, B^{2}(001)$

(') $T_{\text {tnvitbility }} \quad$ was $203{ }^{\circ} \mathrm{C}$ for $\mathrm{Cu}-18.5$ at pct $\mathrm{Au}, 358{ }^{\circ} \mathrm{C}$ for $\mathrm{C}_{3} \mathrm{Au}, 628$ " $\mathrm{C}$ for $\mathrm{CoPt}_{3}$ as determined by Chen [22].

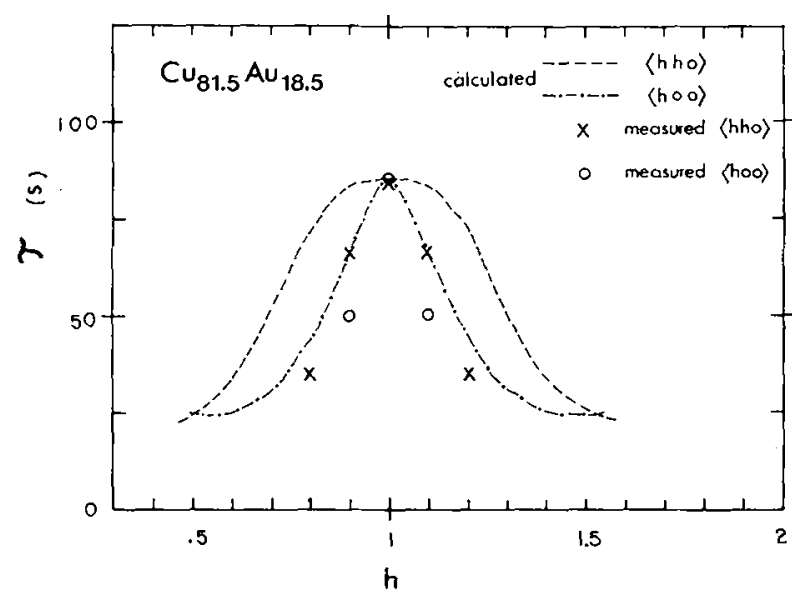

Fig. $3 a$. - The relaxation time $\tau(h)$ es. $h$ for $\mathrm{Cu}_{81.5} \mathrm{Au}_{18.5}$ at $355^{\circ} \mathrm{C} \rightarrow 330^{\circ} \mathrm{C}$ along $\langle h(0)\rangle$ and $\langle h h 0\rangle$ directions. The following values were used for calculations :

$$
\begin{gathered}
a=3.717 \AA, \quad D=0.034 \times \mathrm{e}^{-44.4 k_{\mathrm{B}} T} \mathrm{~cm}^{2} / \mathrm{s}, \\
f^{\prime \prime}=2.05 \times 10^{11} \mathrm{erg} / \mathrm{cm}^{3}, \quad K=-12.2 \times 10^{-6} \mathrm{erg} / \mathrm{cm} ;
\end{gathered}
$$

i.e., the values in table II. The elastic free energy $\left(2 \eta^{2} M(\mathbf{k})\right)$ was calculated as indicated in the Appendix. The experimentally determined $\tau$ 's normalized at the 001 position to the predicted curve are also shown in the figure.

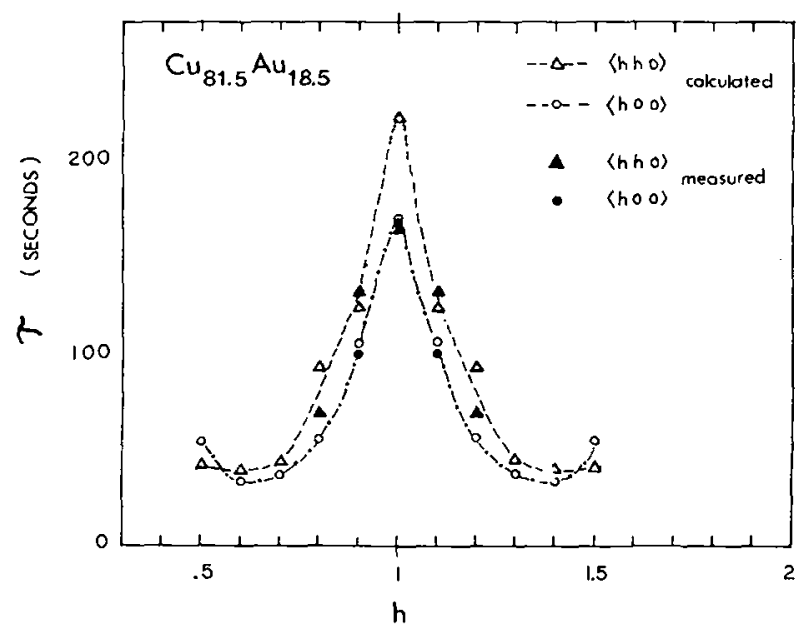

Fig. $3 b$. - The relaxation time estimated with the measured Fouricr representation of total free energy, $F(\mathbf{k})$ (see Table III). Experimental results are also shown.

and the error in the intercept of the least squares fit of figure 4.

The results are compared to other data for this system in table V. The values reported here are in good agreement with tracer studies [35] but not with the work on thin films [8].

3.2.2.2 $\mathrm{Cu}_{3} \mathrm{Au}$. - The kinetics are so rapid in this alloy that measurements could only be made at the superlattice position, and within $4-5{ }^{\circ} \mathrm{C}$ of $T_{\mathrm{c}}$. Because of this small temperature range no activation 


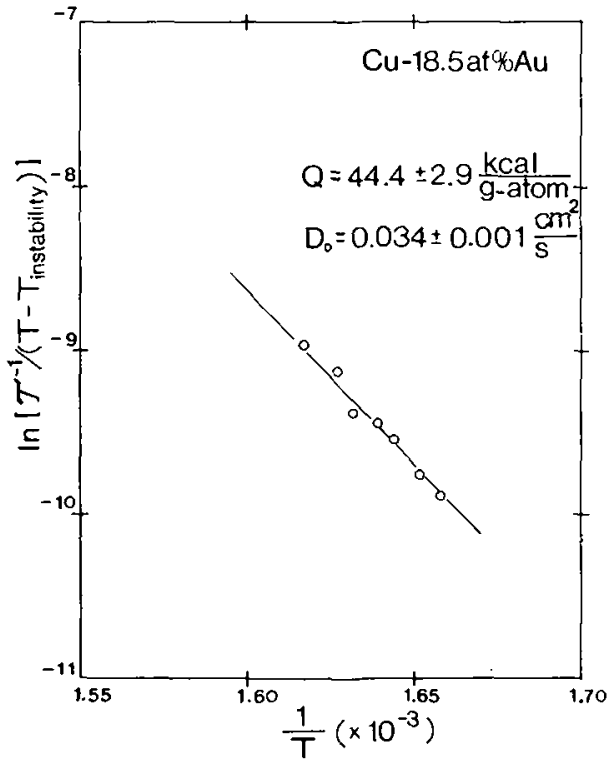

FIG. 4. $-\ln \left[\tau^{-1}(001) / T-T_{\text {instability }}\right]$ vis. $1 / T$ for $\mathrm{Cu}_{81.5} \mathrm{Au}_{18.5}$, quenched from $25-30^{\circ} \mathrm{C}$ above to the indicated temperatures.

\section{TABLE Va}

\section{Interdiffusion coefficient for $\mathrm{Cu}-\mathrm{Au}$ alloys}

\begin{tabular}{lccc}
\multicolumn{1}{c}{ Alloy } & $Q$ (kcal/mole $)$ & $D_{0}\left(\mathrm{~cm}^{2} / \mathrm{s}\right)$ & $\begin{array}{c}\text { rature } \\
\text { Range }\left({ }^{\circ} \mathrm{C}\right)\end{array}$ \\
- & - & - & - \\
$\mathrm{Cu}_{3} \mathrm{Au}\left({ }^{a}\right)$ & $34.0( \pm 3.3)$ & $0.0043( \pm 0.0005)$ & $665-800$ \\
$\mathrm{Cu}_{0.8} \mathrm{Au}_{0.2}\left({ }^{a}\right)$ & $41.6( \pm 3.9)$ & 0.107 & $665-800$ \\
$\mathrm{Cu}_{81.5} \mathrm{Au}_{18.5}\left(^{({ })}\right.$ & $44.4( \pm 2.9)$ & $0.034( \pm 0.001)$ & $330-345.5$ \\
$\mathrm{Cu}_{84.0} \mathrm{Au}_{16.0}\left({ }^{a}\right)$ & $33.8( \pm 5.2)$ & 0.001 & $200-260$ \\
$\mathrm{Cu}_{90.0} \mathrm{Au}_{10.0}\left({ }^{a}\right)$ & $34.4( \pm 8.7)$ & 0.0018 & $665-800$
\end{tabular}

TABLE $\mathrm{V} b$

Self diffusivity and tracer diffusivity in $\mathrm{Cu}-\mathrm{Au}$ alloys

$\begin{array}{cccc}\begin{array}{c}\text { Self } \\ \text { diffusivity }\end{array} & Q(\mathrm{kcal} / \mathrm{mole}) & D_{0}\left(\mathrm{~cm}^{2} / \mathrm{s}\right) & \begin{array}{c}\text { Tempe- } \\ \text { rature } \\ \text { Range }\left({ }^{\circ} \mathrm{C}\right)\end{array} \\ \begin{array}{c}\mathrm{Au} \text { in } \mathrm{Au}^{(33)} \\ \mathrm{Cu} \text { in } \mathrm{Cu}^{(34)}\end{array} & 41.70( \pm 0.3) & 0.091( \pm 0.001) & - \\ & 47.12( \pm 0.3) & 0.200( \pm 0.030) & \\ \begin{array}{c}\text { Tracer } \\ \text { diffusivity }\end{array} & Q(\mathrm{kcal} / \mathrm{mole}) & D_{0}\left(\mathrm{~cm}^{2} / \mathrm{s}\right) & \begin{array}{c}\text { Tempe- } \\ \text { rature } \\ \text { Range }\left({ }^{\circ} \mathrm{C}\right)\end{array} \\ \mathrm{Au} \text { in } \mathrm{Cu}^{(35)} & 42.6( \pm 1.0) & 0.030( \pm 0.002) & 400-1050 \\ \mathrm{Cu} \text { in } \mathrm{Au}^{(36)} & 40.65 & 0.105 & 700-906\end{array}$

(') Data obtained from reference [8].

$($ (b) Current result. energies were determined. Furthermore, these temperatures are now known to be within the range above $T_{\mathrm{c}}$ where there are heterophase fluctuations [25], not classical fluctuations. Accordingly, the values were plotted as shown in figure 5 along with the data for $\mathrm{Cu}-18.5$ at pct $\mathrm{Au}$, with corrections for the known $B^{2}(001), f^{\prime \prime}$ and $\Delta S_{\mathrm{m}}^{\prime \prime}$ for each alloy. The points for $\mathrm{Cu}_{3} \mathrm{Au}$ are clearly above those for $\mathrm{Cu}-18.5$ at pct $\mathrm{Au}$; the relaxation times are less than those estimated from the data on $\mathrm{Cu}-18.5$ at pct $\mathrm{Au}$.

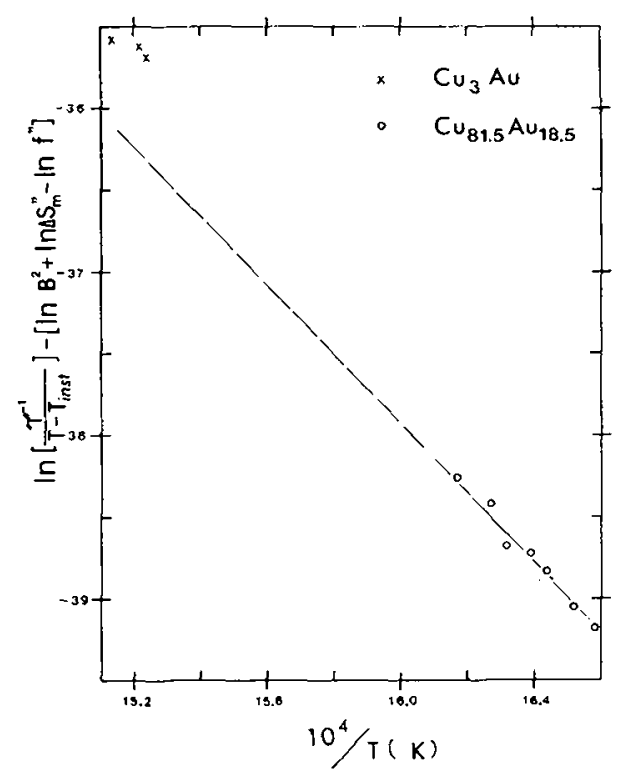

FIG. 5. $-\left\{\ln \left[\tau^{-1}(001) T-T_{\text {instability }}\right]-\left[\ln B^{2}(001)+\ln \Delta S_{\mathrm{m}}^{\prime \prime}-\ln f^{\prime \prime}\right]\right\}$ vs. $1 / T$ for both $\mathrm{Cu}_{81.5} \mathrm{Au}_{18.5}$ and $\mathrm{Cu}_{3} \mathrm{Au}$. (Error is less than the size of the symbol.)

From measurements of relaxation obtained by following changes in Young's modulus obtained by Weisberg and Quimby [37], $\tau$ was $14.1 \pm 0.3 \mathrm{~s}$ at $T_{\mathrm{c}}+0.5{ }^{\circ} \mathrm{C}$, in good agreement with the results of this study, $11.7 \pm 0.1 \mathrm{~s}$.

3.2.2.3 $\mathrm{CoPt}_{3}$. - The data for determining $D_{0}$ and $Q$ are shown in figure 6 . The activation energy is slightly larger than that measured for antiphase domain growth below $T_{\mathrm{c}}$ [38], $63 \mathrm{kcal} / \mathrm{mole}$. The values for self-diffusion in $\mathrm{Co}$ and $\mathrm{Pt}$ are 68 and $65 \mathrm{kcal} / \mathrm{mole}$, respectively [39].

3.2.2.4 Fe-29.2 at pct Al. - Measurable relaxation times could be obtained only $100^{\circ} \mathrm{C}$ below $T_{\mathrm{c}}$ $\left(525^{\circ} \mathrm{C}\right)$. At higher temperatures, the reaction was too rapid. Kinetic measurements were therefore made between 307 and $416^{\circ} \mathrm{C}$. Both quenching and heating were employed, and there was little difference. The results are shown in figure 7. (The term $D_{0}$ could not be obtained, since $K, \Delta S_{\mathrm{m}}^{\prime \prime}$, etc, were not available.) No data on the diffusivities in the ordered phase are available, but the results are much closer to the activation energy for self-diffusion in $\mathrm{Al}$ than that in $\mathrm{Fe}$ [34]. 


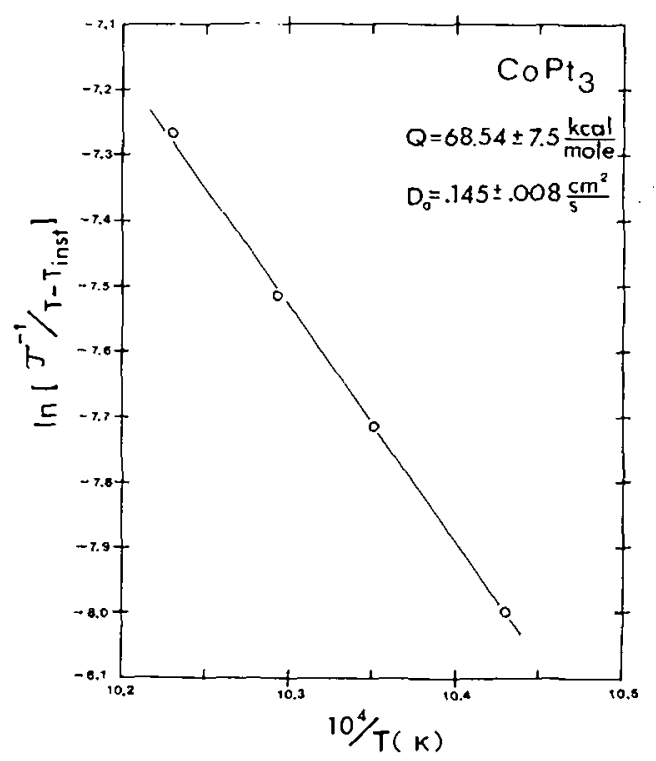

FIG. 6. $-\ln \left[\tau^{-1}(001) / T-T_{\text {instability }}\right]$ tr. $1 / T$ for $\mathrm{CoPt}_{3}$. (Error is less than the size of the circles.

4. Conclusions. - 4.1 Results are reported here for the first time on the values of the transform of the Helmholtz free energy $v s$. wavelength of composition fluctuations in alloys with local order, and on the variation in relaxation time of these fluctuations $v s$. crystallographic direction. These results clearly indicate that the nearest-neighbour approximations in the theory of continuous ordering are indequate. The gradient energy is a strong function of the wavelength and crystallographic direction.

4.2 A technique has been demonstrated for measuring the interdiffusion coefficient at low temperatures in bulk alloy crystals. This method involves measurements of the absolute intensity due to local order $v s$. temperature in the range of interest, and measurement of the changes in diffuse intensity with time for small temperature changes in this range.

4.3 A study similar to this one but above a miscibility gap would be of considerable interest as a

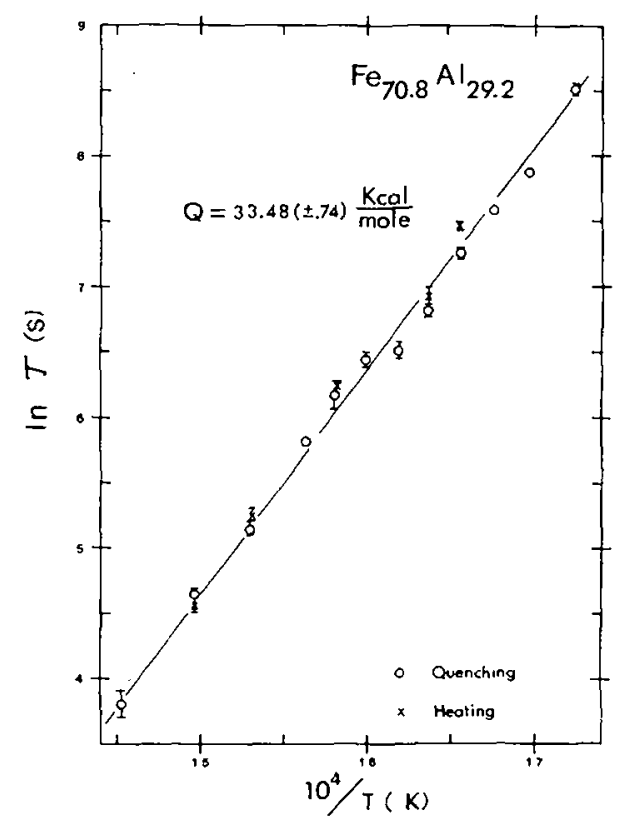

FiG. 7. $-\ln [\tau(1 / 2,1 / 2,1 / 2)]$ vs. $1 / T$ for $\mathrm{Fe}_{70.8} \mathrm{Al}_{29.2}$.

more quantitative test of the theory of spinodal decomposition than has heretofore been obtained.

Acknowledgments. - This research was supported by the U.S. National Science Foundation and constitutes a portion of the $\mathrm{Ph}$. D. thesis submitted by one of the authors (H. C.) in partial fulfilment of the requirements for the $\mathrm{Ph}$. $\mathrm{D}$. degree at Northwestern University. The $\mathrm{X}$-ray studies were carried out in the Long-Term X-Ray Facility of Northwestern University's Materials Research Center, supported by NSF under Grant No. DMR 760157.

The authors would especially like to thank Prof. F. Kayser, Iowa State University for the loan of a single crystal of Cu-18.5 at pet Au, and Dr. L. Guttman for crystals of Fe-29.2 at pet Al. Mr. Robert Lloyd designed the computer interface for monitoring the temperature. Profs. L. H. Schwartz, J. E. Hilliard, H. Cook and Dr. L. Guttman provided valuable discussions.

Appendix. - Following Cook and de Fontaine [5] the elastic free energy of a crystal may be written as follows, starting with a harmonic expansion in terms of transforms of deviations $q$ and $u$ from the average composition and the average lattice, respectively :

with :

$$
F_{\mathrm{e}}=\frac{N}{2} \sum_{\mathbf{k} \in \mathbf{R}} F_{\mathrm{e}}(\mathbf{k}) Q^{*}(\mathbf{k}) Q(\mathbf{k}),
$$

$$
F_{\mathrm{e}}(\mathbf{k})=\Phi(\mathbf{k})-\sum_{i j} \Phi_{i}(\mathbf{k}) \tilde{\Phi}_{i j}(\mathbf{k}) \Phi_{j}(\mathbf{k})^{*},
$$

where $\Phi(\mathbf{k}), \Phi_{i}(\mathbf{k})$ and $\Phi_{i j}(\mathbf{k})$ are Fourier transforms of solute $\left(\varphi\left(r, r^{\prime}\right)\right)$, solute-lattice $\left(\varphi_{i}\left(r, r^{\prime}\right)\right)$ and lattice- 
lattice coupling parameters $\left(\varphi_{i j}\left(r, r^{\prime}\right)\right)$, (C.P.'s), respectively; $\tilde{\Phi}_{i j}(\mathbf{k})$ is the inverse matrix component of matrix $\Phi_{i j}(\mathbf{k})$ and $\Phi_{j}^{*}(\mathbf{k})$ is the complex conjugate of $\Phi_{j}(\mathbf{k})$ :

$$
\varphi\left(r, r^{\prime}\right)=\frac{\partial^{2} F_{\mathrm{c}}}{\partial q(r) \partial q\left(r^{\prime}\right)}, \quad \varphi_{i}\left(r, r^{\prime}\right)=\frac{\partial^{2} F_{\mathrm{c}}}{\partial u_{i}(r) \partial q\left(r^{\prime}\right)}, \quad \varphi_{i j}\left(r, r^{\prime}\right)=\frac{\partial^{2} F_{\mathrm{e}}}{\partial u_{i}(r) \partial u_{j}\left(r^{\prime}\right)}
$$

The product, $Q^{*}(\mathbf{k}) Q(\mathbf{k})$, can be interpreted as the solute intensity related to $I_{\mathrm{SRO}}(\mathbf{k})$, per atom. $F_{\mathrm{e}}(\mathbf{k})$ is normally a function of wavelength as well as a function of the crystallographical direction.

Following the nomenclature used by Born [41], the appropriate Fourier transformations of coupling constants for both fcc and bcc materials are listed in table A.1, employing shorthand notations for the C.P.'s as defined for example by Walker [42]. (C.P.'s beyond the third coordinate shell are assumed here to be zero.) Then, an effective elastic modulus $M(\mathbf{k})$ is defined for cubic crystals as :

$$
M(\mathbf{k})=\frac{F_{\mathbf{c}}(\mathbf{k})}{2 \Omega \eta^{2}},
$$

where $\eta$ is the linear expansion coefficient per unit composition change, $\eta=\frac{\partial \ln a}{\partial c}$ and $\Omega$ is the atomic unit volume.

1) FirSt-Sheli. Model. - a) fec Structure. - - In the derivation, only nearest-neighbour interactions are considered, such that only $\alpha_{1}, \bar{\alpha}_{1}, \hat{\alpha}_{1}, \beta_{1}$ and $\gamma_{1}$ (Table A.1) are non-zero. Therefore, with the long wavelength relationships (Table A.2) the Fourier transforms of the coupling parameters can be written as follows, with the continuous variables in reciprocal space, $h_{1}, h_{2}, h_{3}$ :

$$
\begin{aligned}
\Phi_{11}\left(h_{1}, h_{2}, h_{3}\right) & =a c_{11}\left(2-\cos \pi h_{1} \cos \pi h_{2}-\cos \pi h_{1} \cos \pi h_{3}\right)+2 a c_{44}-\frac{1}{2} c_{11} \quad\left(1-\cos \pi h_{2} \cos \pi h_{3}\right) \\
\Phi_{12}\left(h_{1}, h_{2}, h_{3}\right) & =\Phi_{21}\left(h_{1}, h_{2}, h_{3}\right)=a\left(c_{12}+c_{44}\right) \sin \pi h_{1} \sin \pi h_{2} \\
\Phi_{1}\left(h_{1}, h_{2}, h_{3}\right) & =i\left[\frac{1}{4} a^{2} \eta\left(c_{11}+2 c_{12}\right) \sin \pi h_{1}\left(\cos \pi h_{2}+\cos \pi h_{3}\right)\right]
\end{aligned}
$$

TABLE A. 1

(a) Fourier transforms of bcc coupling parameters (*)

$$
\begin{gathered}
\Phi_{11}\left(h_{1}, h_{2}, h_{3}\right)=8 \alpha_{1}\left(1-\cos \pi h_{1} \cos \pi h_{2} \cos \pi h_{3}\right)+2 \alpha_{2}\left(1-\cos 2 \pi h_{1}\right)+ \\
+2 \beta_{2}\left(2-\cos 2 \pi h_{2}-\cos 2 \pi h_{3}\right)+4 \beta_{3}\left(1-\cos 2 \pi h_{2} \cos 2 \pi h_{3}\right) \\
+4 \alpha_{3}\left[2-\cos 2 \pi h_{1}\left(\cos 2 \pi h_{2}+\cos 2 \pi h_{3}\right)\right] \\
\Phi_{12}\left(h_{1}, h_{2}, h_{3}\right)=8 \gamma_{1} \sin \pi h_{1} \sin \pi h_{2} \sin \pi h_{3}+4 \gamma_{3} \sin 2 \pi h_{1} \sin 2 \pi h_{2} \\
\Phi_{1}\left(h_{1}, h_{2}, h_{3}\right)=i\left[8 \hat{\alpha}_{1} \sin \pi h_{1} \cos \pi h_{2} \cos \pi h_{3}+2 \hat{\alpha}_{2} \sin 2 \pi h_{1}+4 \hat{\alpha}_{3} \sin 2 \pi h_{1}\left(\cos 2 \pi h_{2}+\cos 2 \pi h_{3}\right)\right] \\
\Phi\left(h_{1}, h_{2}, h_{3}\right)=8 \bar{\alpha}_{1}\left(1+\cos \pi h_{1} \cos \pi h_{2} \cos \pi h_{3}\right)+ \\
+4 \bar{\alpha}_{3}\left(3+\cos 2 \pi h_{1} \cos 2 \pi h_{2}+\cos 2 \pi h_{1} \cos 2 \pi h_{3}+\cos 2 \pi h_{2} \cos 2 \pi h_{3}\right) \\
+ \\
+2 \bar{\alpha}_{2}\left(3+\cos 2 \pi h_{1}+\cos 2 \pi h_{2}+\cos 2 \pi h_{3}\right) .
\end{gathered}
$$

(b) Fourier transforms of fec coupling parameters

$$
\begin{aligned}
\Phi_{11}\left(h_{1}, h_{2}, h_{3}\right) & =4 \alpha_{1}\left(2-\cos \pi h_{1} \cos \pi h_{2}-\cos \pi h_{1} \cos \pi h_{3}\right)+4 \beta_{1}\left(1-\cos \pi h_{2} \cos \pi h_{3}\right)+ \\
& +2 \alpha_{2}\left(1-\cos 2 \pi h_{1}\right)+2 \beta_{2}\left(2-\cos 2 \pi h_{2}-\cos 2 \pi h_{3}\right)+8 \alpha_{3}\left(1-\cos 2 \pi h_{1} \cos \pi h_{2} \cos \pi h_{3}\right) \\
& +8 \beta_{3}\left[2-\cos \pi h_{1}\left(\cos 2 \pi h_{2} \cos \pi h_{3}+\cos \pi h_{2} \cos 2 \pi h_{3}\right)\right] \\
\Phi_{12}\left(h_{1}, h_{2}, h_{3}\right)= & 4 \gamma_{1} \sin \pi h_{1} \sin \pi h_{2}+8 \gamma_{3} \sin \pi h_{1} \sin \pi h_{2} v \cos 2 \pi h_{3}+ \\
& +8 \delta_{3} \cos \pi h_{3}\left(\sin 2 \pi h_{1} \sin \pi h_{2}+\sin \pi h_{1} \sin 2 \pi h_{2}\right) \\
\Phi_{1}\left(h_{1}, h_{2}, h_{3}\right)= & i\left[4 \hat{\alpha}_{1} \sin \pi h_{1}\left(\cos \pi h_{2}+\cos \pi h_{3}\right)+2 \hat{\alpha}_{2} \sin 2 \pi h_{1}+8 \hat{\alpha}_{3} \sin 2 \pi h_{1} \cos \pi h_{2} \cos \pi h_{3} m+\right. \\
& \left.+8 \hat{\beta}_{3} \sin \pi h_{1}\left(\cos \pi h_{2} \cos 2 \pi h_{3}+\cos \pi h_{3} \cos 2 \pi h_{2}\right)\right] \\
\Phi\left(h_{1}, h_{2}, h_{3}\right)= & 4 \bar{\alpha}_{1}\left(3+\cos \pi h_{1} \cos \pi h_{2}+\cos \pi h_{1} \cos \pi h_{3}+\cos \pi h_{2} \cos \pi h_{3}\right)+ \\
+ & 2 \bar{\alpha}_{2}\left(3+\cos 2 \pi h_{1}+\cos 2 \pi h_{2}+\cos 2 \pi h_{3}\right) \\
+ & 8 \bar{\alpha}_{3}\left(3+\cos \pi h_{1} \cos \pi h_{2} \cos 2 \pi h_{3}+\cos \pi h_{1} \cos 2 \pi h_{2} \cos \pi h_{3}+\cos 2 \pi h_{1} \cos \pi h_{2} \cos \pi h_{3}\right) .
\end{aligned}
$$

(*) C.P.'s beyond the third shell are assumed to be zero. 
and :

$$
\Phi\left(h_{1}, h_{2}, h_{3}\right)=4 \bar{\alpha}_{1}\left(3+\cos \pi h_{1} \cos \pi h_{2}+\cos \pi h_{3} \cos \pi h_{1}+\cos \pi h_{2} \cos \pi h_{3}\right) .
$$

The rest of the terms appearing in Eq. (A . $1 b$ ) can be obtained by permutations among $h_{1}, h_{2}$ and $h_{3}$. The shorthand notation for solute coupling constants, $\bar{\alpha}_{1}$, can be expressed in terms of the lattice coupling constants using Eq. (41) in reference [5], which, for cubic crystals is :

$$
\varphi(r)=\eta \varphi_{i}(r) x_{i}(r)+\frac{1}{4} S(i i j j) \eta^{2} \varphi_{i j}(r) x_{i}(r) x_{j}(r)
$$

where :

$$
S(i i j j)=\left\{\begin{array}{ccc}
1 & \text { if } & i=j \\
\frac{2 c_{12}}{c_{12}+c_{44}} & \text { if } & i \neq j
\end{array}\right.
$$

and $x_{i}(r)$ are the components of an interatomic vector in real space. Then, with the shorthand notations for the C.P.'s defined by Walker [42] :

$$
\begin{aligned}
\varphi\left(\frac{1}{2}, 0, \frac{1}{2}\right)=\bar{\alpha}_{1}= & \frac{1}{2} a \eta\left[\varphi_{1}\left(\frac{1}{2}, 0, \frac{1}{2}\right)+\varphi_{3}\left(\frac{1}{2}, 0, \frac{1}{2}\right)\right]+\frac{1}{16} a^{2} \eta^{2}\left[\varphi_{11}\left(\frac{1}{2}, 0, \frac{1}{2}\right)+\varphi_{33}\left(\frac{1}{2}, 0, \frac{1}{2}\right)\right]+ \\
& +\frac{1}{4} a^{2} \eta^{2} \frac{c_{12}}{c_{12}+c_{44}} \varphi_{13}\left(\frac{1}{2} 0 . \frac{1}{2}\right)=a \eta \hat{\alpha}_{1}-\frac{1}{8} a^{2} \eta^{2} \alpha_{1}-\frac{1}{4} \frac{c_{12}}{c_{12}+c_{44}} a^{2} \eta^{2} \gamma_{1}
\end{aligned}
$$

and :

$$
\bar{\alpha}_{1}=\frac{1}{32} a^{3} \eta^{2}\left(c_{11}+2 c_{12}\right)
$$

The effective modulus can now be expressed along three crystallographic directions. For the $\langle h 00\rangle$ direction with $h_{1}=h$ and $h_{2}=h_{3}=0$, Eq. (A.4) becomes :

$$
\begin{aligned}
\Phi_{11}(h 00) & =2 a c_{11}(1-\cos \pi h) \\
\Phi_{22}(h 00) & =\Phi_{33}(h 00)=2 a c_{44}(1-\cos \pi h) \\
\Phi_{12}(h 00) & =\Phi_{21}(h 00)=\Phi_{13}(h 00)=\Phi_{31}(h 00)=\Phi_{23}(h 00)=\Phi_{32}(h 00)=0 \\
\Phi_{1}(h 00) & =i\left[\frac{1}{2} a^{2} \eta\left(c_{11}+2 c_{12}\right) \sin \pi h\right] \\
\Phi_{2}(h 00) & =\Phi_{3}(h 00)=0 \\
\Phi(h 00) & =\frac{1}{4} a^{3} \eta^{2}\left(c_{11}+2 c_{12}\right)(2+\cos \pi h)
\end{aligned}
$$

The inverse matrix $\left\{\widetilde{\Phi}_{i j}(h 00)\right\}$ is obtained from the matrix $\left\{\Phi_{i j}(h 00)\right\}$ :

$$
\left\{\tilde{\Phi}_{i j}(h 00)\right\}=\left|\begin{array}{ccc}
\frac{1}{2 a c_{11}(1-\cos \pi h)} & 0 & 0 \\
0 & \frac{1}{2 a c_{44}(1-\cos \pi h)} & 0 \\
0 & 0 & \frac{1}{2 a c_{44}(1-\cos \pi h)}
\end{array}\right|
$$

Therefore, the elastical free energy $F_{\mathrm{e}}(h 00)$ in its Fourier representation is obtained from Eq. (A. $\left.1 b\right)$ :

$$
F_{e}(h 00)=\frac{1}{8} a^{3} \eta^{2}\left(c_{11}+2 c_{12}\right)\left[3-2 \frac{c_{12}}{c_{11}}+\left(1-2 \frac{c_{12}}{c_{11}}\right) \cos \pi h\right],
$$


and subsequently the effective elastical modulus $M(h 00)$ is :

$$
M(h 00)=\frac{F_{\mathrm{e}}(h 00)}{2 \Omega \eta^{2}}=\frac{1}{2}\left(c_{11}+2 c_{12}\right)\left[\frac{3}{2}-\frac{c_{12}}{c_{11}}+\left(\frac{1}{2}-\frac{c_{12}}{c_{11}}\right) \cos \pi h\right] .
$$

Similarly for the $\langle h h 0\rangle$ direction :

$$
M(h h 0)=\frac{1}{4} c_{11}\left[\left(1+2 \frac{c_{12}}{c_{11}}\right)\left(3+2 \cos \pi h+\cos ^{2} \pi h\right)-\frac{\left(1+2 \frac{c_{12}}{c_{11}}\right)^{2}(1+\cos \pi h)^{3}}{\frac{2 c_{44}}{c_{11}}+\left(1+\frac{c_{12}}{c_{11}}+\frac{c_{44}}{c_{11}}\right)(1+\cos \pi h)}\right] .
$$

For the $\langle h h h\rangle$ direction :

$$
M(h h h)=\frac{3}{4}\left(c_{11}+2 c_{12}\right)\left(1+\cos ^{2} \pi h\right)+\frac{3}{2} \frac{\left(c_{11}+2 c_{12}\right)^{2}\left[3+\left(\frac{c_{11}+2 c_{44}}{c_{12}+c_{44}}\right)^{2}\right] \sin ^{2} \pi h \cos ^{2} \pi h}{\left(c_{12}+c_{44}\right)\left(2+\frac{c_{11}+2 c_{44}}{c_{12}+c_{44}}\right)\left[1-\left(\frac{c_{11}+2 c_{44}}{c_{12}+c_{44}}\right)^{2}\right]} .
$$

b) bbc Structure. - Assuming all the nearest-neighbour coupling constants plus $\beta_{2}$ are non-zero, the Fourier transforms of the coupling constants for a bec system (Table A.1) are given by :

and

$$
\begin{aligned}
\Phi\left(h_{1}, h_{2}, h_{3}\right) & =8 \bar{\alpha}_{1}\left(1+\cos \pi h_{1} \cos \pi h_{2} \cos \pi h_{3}\right), \\
\Phi_{1}\left(h_{1}, h_{2}, h_{3}\right) & =8 i \hat{\alpha}_{1} \sin \pi h_{1} \cos \pi h_{2} \cos \pi h_{3}, \\
\Phi_{11}\left(h_{1}, h_{2}, h_{3}\right) & =8 \alpha_{1}\left(1-\cos \pi h_{1} \cos \pi h_{2} \cos \pi h_{3}\right)+2 \beta_{2}\left(2-\cos \pi h_{2}-\cos 2 \pi h_{3}\right),
\end{aligned}
$$

$$
\Phi_{12}\left(h_{1}, h_{2}, h_{3}\right)=8 \gamma_{1} \sin \pi h_{1} \sin \pi h_{2} \sin \pi h_{3} \text {. }
$$

From the long wavelength relationships (Table A.2) :

$$
\begin{aligned}
& \alpha_{1}=\frac{1}{2} a c_{11}, \quad \beta_{2}=\frac{1}{2} a\left(c_{44}-c_{11}\right), \quad \gamma_{1}=\frac{1}{4} a\left(c_{44}+c_{12}\right), \\
& \hat{\alpha}_{1}=\frac{1}{8} a^{2} \eta\left(c_{11}+2 c_{12}\right), \quad \text { and } \quad \bar{\alpha}_{1}=\frac{3}{32} a^{3} \eta^{2}\left(c_{11}+2 c_{12}\right) .
\end{aligned}
$$

The effective modulus will again be calculated along three simple crystallographic directions. For the $\langle h 00\rangle$ direction :

$$
M(h 00)=\frac{1}{4}\left(c_{11}+2 c_{12}\right)\left(3-c_{11}-2 c_{12}\right)(1+\cos \pi h) .
$$

For the $\langle h h 0\rangle$ direction :

$$
M(h h 0)=\frac{3}{4}\left(c_{11}+2 c_{12}\right)\left(1+\cos ^{2} \pi h\right)-\frac{\left(c_{11}+2 c_{12}\right)^{2}}{c_{11}+c_{12}+2 c_{44}} \cos ^{2} \pi h .
$$

For the $\langle h h h\rangle$ direction :

$$
\begin{array}{r}
M(h h h)=\frac{3}{4}\left(c_{11}+2 c_{12}\right)\left[1+\cos ^{3} \pi h-\frac{\left(c_{11}+2 c_{12}\right) \sin ^{2} \pi h \cos ^{4} \pi h}{c_{11}(1-\cos \pi h)+\left(c_{11}+c_{12}+c_{44}\right) \sin ^{2} \pi h \cos \pi h}\right]+ \\
+\left(c_{44}-c_{11}\right) \sin ^{2} \pi h .
\end{array}
$$

The elastic constants employed in this work are given in table A.3. 
TABLE A.2

Long wavelength relations for coupling parameters. (All C.P.'s beyond the third coordination shell are assumed to be zero.).

(i) bcc

$$
\begin{aligned}
& 2 \alpha_{1}+2 \alpha_{2}+8 \alpha_{3}=a C_{11} \\
& 2 \alpha_{1}+2 \beta_{2}+4 \alpha_{3}+4 \beta_{3}=a C_{44} \\
& 4 \gamma_{1}+8 \gamma_{3}=a\left(C_{11}+2 C_{12}\right) \\
& 4 \hat{\alpha}_{1}+2 \hat{\alpha}_{2}+8 \hat{\alpha}_{3}=\frac{1}{2} a^{2} \eta\left(C_{11}+2 C_{12}\right)
\end{aligned}
$$

(ii) fcc

$$
\begin{aligned}
& 4 \alpha_{1}+4 \alpha_{2}+16 \alpha_{3}+8 \beta_{3}=a C_{11} \\
& 2 \alpha_{1}+2 \beta_{1}+4 \beta_{2}+4 \alpha_{3}+20 \beta_{3}=a C_{44} \\
& 4 \gamma_{1}+8 \gamma_{3}+32 \delta_{3}=a\left(C_{44}+C_{12}\right) \\
& 8 \hat{\alpha}_{1}+4 \hat{\alpha}_{2}+16\left(\hat{\alpha}_{3}+\hat{\beta}_{3}\right)=\frac{1}{2} a^{2} \eta\left(C_{11}+2 C_{12}\right)
\end{aligned}
$$

\begin{tabular}{|c|c|c|c|}
\hline System & $\frac{C_{11}}{\left(\times \overline{10^{12}}\right)}$ & $\frac{C_{12}}{\left(\times 10^{12}\right)}$ & $\frac{C_{44}}{\left(\times 10^{12}\right)}$ \\
\hline $\mathrm{Cu}_{3}$ & 1.590 & 1.246 & 0.549 \\
\hline $\mathrm{d}_{81.5} \mathrm{Au}$ & 1.795 & 1.355 & 0.589 \\
\hline $\mathrm{CoPt}_{3}$ & 3.077 & 2.193 & 0.735 \\
\hline $\mathrm{Fe}_{70.8} \mathrm{Al}_{29.2}(\mathrm{c})$ & 1.664 & 1.226 & 1.310 \\
\hline
\end{tabular}

where $C_{11}, C_{12}$ and $C_{44}$ are the usual elastic constants.
TABLE A. 3

Elastic constants employed to estimate strain energies, $2 \eta^{2} M(\mathbf{k})$ (units are dyne $/ \mathrm{cm}^{2}$ )

$\left({ }^{a}\right)$ Elastic constants for $\mathrm{Cu}_{3} \mathrm{Au}$ were taken from Siegel's [43] measurements at $420{ }^{\circ} \mathrm{C}$. No data were available for $\mathrm{Cu}_{81.5} \mathrm{Au}_{18.5}$ alloy; interpolated data [44] from pure copper to $\mathrm{Cu}_{3} \mathrm{Au}$ at $355^{\circ} \mathrm{C}$ were used.

(b) Elastic constants for $\mathrm{CoPt}_{3}$ at $680^{\circ} \mathrm{C}$ were interpolated between those measured for $\mathrm{Pt}[45]$ at $25^{\circ} \mathrm{C}$ and for fce $\mathrm{Co}$ [46].

(c) Elastic constants for $\mathrm{Fe}_{70,8} \mathrm{Al}_{29,2}$ were from those measured at room temperature for $\mathrm{Fe}_{71,90} \mathrm{Al}_{28,08}$ [44].

2) Quasi-Three-Shell Model. - Lattice C.P.'s can be normally measured using inelastic neutron scattering techniques. The solute and solute-lattice C.P.'s can only be determined from elastic constants using the long wavelength relations $\left({ }^{2}\right.$ ) (Table A .2) and Eq. (A.5). To do this, however, one has to assume a nearestneighbour interaction, that is, all solute and solute-lattice C.P.'s except for $\hat{\alpha}_{1}$ and $\bar{\alpha}_{1}$ are zero. Under these conditions, the following equations are obtained from the long wavelength relations (Table A.2) and Eq. (A.6a) for an fcc structure :

and :

$$
\hat{\alpha}_{1}=\frac{1}{16} a^{2} \eta\left(c_{11}+2 c_{12}\right)
$$

$$
\bar{\alpha}_{1}=a \eta \alpha_{1}-\frac{\alpha_{1} a^{2} \eta}{8}-\frac{c_{12} a^{2} \eta^{2} \gamma_{1}}{4\left(c_{12}+c_{44}\right)}
$$

Therefore, a quasi-three-shell model (which assumes that $\alpha_{1}, \alpha_{2}, \alpha_{3}, \beta_{1}, \beta_{2}, \beta_{3}, \gamma_{1}, \gamma_{3}, \delta_{3}$, plus $\hat{\alpha}_{1}$ and $\bar{\alpha}_{1}$ are nonzero) may be assumed to obtain the effective elastic modulus along the $\langle h 00\rangle$ and $\langle h h 0\rangle$ lines for an fcc structure. Hence :

$$
M(h 00)=\frac{2}{a^{3} \eta^{2}}\left[8 \bar{\alpha}_{1}(2+\cos \pi h)-\frac{8 \hat{\alpha}_{1} \sin \pi h}{\left(8 \alpha_{1}+16 \beta_{3}\right)(1-\cos \pi h)+\left(2 \alpha_{2}+8 \alpha_{3}\right)(1-\cos 2 \pi h)}\right]
$$

and :

$$
\begin{aligned}
& M(h h 0)=\frac{2}{a^{3} \eta^{2}} \times \\
& \begin{aligned}
\times 4 \bar{\alpha}_{1}\left(3+2 \cos \pi h+\cos ^{2} \pi h\right)- & \frac{8 \hat{\alpha}_{1} \sin \pi h(1+\cos \pi h)}{\left.4 \alpha_{1}\left(2-\cos \pi h-\cos ^{2} \pi h\right)+4 \beta_{1}(1-\cos \pi h)+2 \alpha_{2}+2 \beta_{2}\right)(1-\cos 2 \pi h)+} \\
& +8 \alpha_{3}\left(1-\cos \pi h \cos ^{2} \pi h\right)+16 \delta_{3} \sin \pi h \sin 2 \pi h \\
& +4 \beta_{3}\left(1-\cos 2 \pi h-\cos ^{2} \pi h\right)+\left(4 \gamma_{1}+8 \alpha_{3}\right) \sin ^{2} \pi h .
\end{aligned}
\end{aligned}
$$

${ }^{2}$ ) An attempt was made by Gragg and Bardhan [47] to evaluate the force constants using the X-ray diffuse scattering pattern due to local atomic order and static atomic displacements. However, the analysis indicated large errors. 


\section{References}

[1] CoOK, H. E., Materials Science \& Engineering 25 (1976) 127.

[2] Со०K, H. E., J. Phys. \& Chem. Solids 30 (1968) 1097 ; 30 (1968) 2427.

[3] Cook, H. E., de Fontaine, D. and Hilliard, J. E., Acta Met. 17 (1969) 765.

[4] De Fontaine, D. and Cook, H. E., Critical Phenomena in Alloys, Magnets and Superconductors, ed. by R. E. Mills, E. Ascher and R. I. Jaffee (McGraw-Hill) 1971, p. 257.

[5] CoOK, H. E. and de Fontaine, D., Acta Met. 17 (1969) 915.

[6] YamauchI, H., Master's Thesis, Northwestern University, Evanston, Illinois (1971)

[7] Acuña, R. and Bonfiglioli, A., Acta Met. 22 (1974) 399.

[8] Paulsen, W. M. and Hilliard, J. E., J. Appl. Phys., in press.

[9] Naumora, N. M., Semenovskaya, S. V. and Umanskil, Ya. S.. Sov. Phys. Solid State 12 (1970) 764.

[10] Schwartz, L. H. and Cohen, J. B., J. Appl. Phys. 36 (1965) 598.

[11] Gehlen, P. C. and Cohen, J. B., J. Appl. Phys. 40 (1969) 5193.

[12] Berg, H. and Cohen, J. B., Acta Met. 21 (1973) 1579.

[13] Kayser, F., Ames Laboratory, Iowa State University, private communication.

[14] Gutrman, L. and Schnyders, H. C., Phys. Rev. Lelt. 22 (1969) 520.

[15] De WolfF, P. M., Acta Crystallogr. 2 (1956) 682.

[16] SuORtTi, P., J. Appl. Crystallogr. 5 (1972) 325.

[17] SChwartZ, L. H., MORRison, L. A. and COHEN, J. B., Advances in $X$-Ray Analysis 7 ed. by J. B. Newkirk (Plenum Press) 1963, p. 281.

[18] GragG, J., Ph. D. Thesis, Northwestern University, Evanston, Illinois (1970).

[19] Chipman, D., private communication.

[20] SCHWARTZ, L. H. and COHEN, J. B., Diffraction from Materials (Academic Press, New York) in press.

[21] Bardhan, P. and Cohen, J. B., Acta Crystallogr. A 32 (1976) 597.

[22] Chen, H., Ph. D. Thesis, Northwestern University, Evanston, Illinois (1977).

[23] BorIE, B. and SPARKs, C. J., Acta Crystallogr. A 27 (1971) 198.

[24] GragG, J. E., Jr. and Cohen, J. B., Acta Met. 19 (1971) 507.
[25] Bardhan, P., Chen, H. and Cohen, J. B., Phil. Mag. 31 (1977) $n^{\circ} 6$.

[26] Selected Values of the Thermodynamic Properties of Binary Alloys, ed. by R. Hultgren et al. (American Society for Mctals, Metals Park, Ohio) 1973.

[27] Rundman, K. B. and Hilliard, J. E., Acta Met. 15 (1967) 1025.

[28] Moss, S. C., Phys. Rev. Lett. 22 (1969) 1108 ;

Wilkins, S., Phys. Rev. B 2 (1970) 3935.

[29] Cahn, J. W. and Hilliard, J. E., J. Chem. Phys. 28 (1958) 258.

[30] Langer, J. S., Acta Met. 21 (1973) 1649.

[31] Damask, A. C., J. Appl. Phys. 27 (1956) 610.

[32] Radelaar, S., J. Phys. \& Chem. Solids 31 (1970) 219.

[33] Makin, S. M., Rowe, A. H. and Le Clatre, A. D., Proc. Phys. Soc. B 70 (1957) 545.

[34] Fradin, F. Y., US Atomic Energy Comm. Report, COO$1198-486$ (1967) 117.

[35] Chatterjee, A. and Fabian, D. J., Acta Met. 17 (1969) 1141.

[36] Vignes, A. and Haeussler, J. P., C. R. Hebd. Séan. Acad. Sci. C 263 (1966) 1504.

[37] Weisberg, L. R. and Quimby, S. L., J. Phys. \& Chem. Solids 24 (1963) 1251.

[38] Berg, H. and Cohen, J. B., Met. Trans. 3 (1972) 1797 ; Ph. D. Thesis, Northwestern University, Evanston, Illinois (1972).

[39] Smrthei.Ls, C. J., Metals Reference Handbook (Plenum Press, New York) 1967, p. 644.

[40] Badia, M., Ph. D. Thesis, University of Navey, France (1969).

[41] BoRn, M. and HuAng, K., Dynamic Theory of Crystal Lattice (Oxford University Press, Oxford, England) 1954.

[42] Walker, C. B., Phys. Rev. 103 (1956) 547.

[43] Sifgel, S., Phys. Rev. 57 (1940) 537.

[44] Leamy, H. J., Ginson, E. D. and Kayser, F. X., Acta Met. 15 (1967) 1827.

[45] Mac Farlane, R. E. and Rayne, J. A., Phys. Lett. 18 (1965) 91.

[46] Dragsiorf, R. D., J. Appl. Phys. 31 (1960) 434.

[47] Bardhan, P. and Gragg, J. E., Jr., J. Phys. \& Chem. Solids 35 (1974) 717. 